Author's postprint:

SPIJKER, Jeroen; SCHNEIDER, Anna (2021) "The Myth of Old Age: Addressing the Issue of Dependency and Contribution in Old Age Using Empirical Examples From the United Kingdom". Sociological Research Online (First Published 17 August 2020 / ISSN: 1360-7804). https://doi.org/10.1177/1360780420937737 


\title{
The myth of old age: Addressing the issue of dependency and contribution in old age using empirical examples from the UK.
}

\begin{abstract}
In academia, policy-making and the media, population ageing often has negative connotations: it is associated with a rising care burden on society, with dependency, and with a fear of social isolation. The concepts pertaining to old age have evolved over time, and some of them challenge criticise this popular perception. This paper begins with an overview of the development of social attitudes towards old age. Then, with the help of publicly available UK data, it addresses three areas in which old age and population ageing is perceived as problematic: poor health, dependency on other people's productivity and the role older adults play in the care cycle. Due to the diversity of the population aged $65+$ we question the necessity of distinguishing older people in terms of age or dependency and instead recommend more research into the heterogeneity of the older population.
\end{abstract}

\section{Keywords}

Old age, health, life stages, attitudes, social roles, volunteering, caregiving

\section{Introduction}

Policy and science are driven by a focus on problems and their solutions, and population ageing is often identified as a prime reason for concern, typically viewed through the lens of dependence. This dependence is observed in several different areas, for example healthcare resource use, social care needs, and financial dependence on state benefits (pensions). Advancing 
age is correlated with a higher need for health and social care (Howden and Rice, 2018). In combination with higher life expectancy, population ageing is predicted to heighten the pressure on health and social care systems which are already suffering from staff shortages (Health Foundation 2019, European Observatory on Health Systems and Policies 2006). Furthermore, longer life spans mean more years in receipt of state pensions, which has led to all European governments reforming their public pension system during the last couple of decades (Ogg and Rašticová, 2020). This supposed old age 'burden' is, however, a one-sided view of a much more complex socio-demographic development. In a world that is driven by bad news, it is important to highlight the multiple facets of a topic, rather than allowing the societal discourse around older adults to revolve around the paradigm of dependence.

This paper first provides an abbreviated overview of the development of social attitudes towards 'old age' and highlights the social construction of this term. . Subsequently, it analyses several different data sources from the UK to address three areas in which population ageing is perceived as problematic. Due to the complexity of the topic, these areas cannot cover the discourse around old age exhaustively but highlight key issues of policy concern around ageing by looking at them through the lens of a dependency/contribution dichotomy.

The first addressed area is that of poor health. Longer life expectancy is feared to lead to many more years in poor health, but is this actually the case? The second area encompasses financially dependency. Longer periods of time spent claiming a pension are linked to the idea of a lack of contribution to society, both financially and in terms of work. We look at rates of economic inactivity and poverty in various population groups and explore in what ways older adults still contribute to the economy. Thirdly, poor health is assumed to not only lead to 
intensified use of formal healthcare but also to a need for informal care. We explore what role older adults play in the care cycle.

How population groups are discussed in academia, the media, and in policy have a direct effect on how they are perceived in society as a whole, and how they are treated on a one-to-one basis. To counteract common consternation in the face of population ageing (Spijker and MacInnes, 2013a), we therefore need to ensure older adults' portrayal acknowledges their contributions as much as their needs.

\section{Perspectives on Old Age throughout history [THIS SECTION HAS BEEN REDUCED]}

An awareness of several stages or ages of life has manifested for a long time in Western cultures. It shows in rites of passage, such as confirmation, Bar and Bat Mitzvah, marriage etc. However, as Parkin (2003: 2) points out, 'the passage from adulthood to old age was rarely marked by rites of transition'. The attitudes towards older adults throughout history have varied between admiration for their wisdom (evidenced in the right of the old to speak first in the Roman Senate, which gleaned its name from the Latin word 'senectus' for high age) and the perception of the frail elderly as a burden. The latter perception was especially dominant in economically difficult times, such as the late 17th century, when a colder climate led to bad harvests (Münch, 1998; Tölle, 1996).

The raised awareness of old age in Modernity stems from the rise of its significance in the life course. This was attested by Peter Laslett (1996), who, together with Bernice Neugarten (1974), is often named the inventor of the term 'Third Age', despite the historic roots of the concept. Laslett refers to the Third Age as the age of 'personal achievement and fulfilment' after retirement. However, it has only been since the 1950s that the Third Age has been open to 
everyone in Britain and that growing old is now often met with relief (Laslett, 1996). This is for at least two reasons. First, the universal state pension system (in the UK, introduced in 1946) has not only made public support a legitimate right for those who pass a certain age, it has also increased 'resourcefulness' of the recipients (Gilleard and Higgs, 2011). Secondly, improved public health and hygiene and the availability and quality of medical care, had steadily increased the chances of growing old. This process, which had started at the end of the 19th century when infant and child mortality began to decline, has allowed proportionally more people (of all social classes) to actually reach old age. Since the 1970 s, this has been reinforced by the continual improvements in old-age survival rates (Spijker and MacInnes, 2013b).

Due to the lack of a clear definition, social and behavioural scientists have tended to accept governmental definitions of 'pension age' or 'retirement age' as a convenient demarcation line between mature adulthood and old age. However such a heuristic device has at least two defects.

The first is that it this demarcation line is arbitrary and contingent. It does not reflect the diverse employment histories, job demands, social responsibilities, economic circumstances, and health statuses of people. Before the 'retirement age' or 'pension age' became its accepted definition in industrialized countries, old age was more related to appearing old and no longer being able to take care of oneself due to being physically or mentally ill or frail, rather than a question of precise calendar years. Indeed, this is still the case in developing countries, particularly those that offer no pension system (Roebuck, 1979; Holmes and Holmes, 1995).

The second drawback is that the same chronological age of pension eligibility has been associated over time with a steadily increasing remaining life expectancy. Those men and women fortunate enough to reach the age of 65 in the UK in 1900 could look forward to an average of, respectively, 10 and 11 more years of life. Their counterparts today can expect to 
live another 18 and 21 years (www.mortality.org). Moreover, today's Third Age come from a generation who absorbed the 'busy ethic' throughout their lives and feel the need to be perceived as active even when no longer required to work to earn money (Ekerdt, 1986). Others see the origins of such Third Age lifestyle orientation in the dispositions of the 1960s' youth culture, such as autonomy, strong social involvement and self-expression, which have been carried over into later life as this generation has grown older (Gilleard and Higgs, 2010; Schulze, 2005).

These developments have not gone unnoticed by academics, but the typical response in studies is merely a shifting upwards of the age cut-off-line. However in Critical Gerontology, this life course perspective with a fixed idea of life stages has been put into question. Authors like Baars (2012) and Grenier (2012: 19) emphasize 'the constructed nature of the life course'. By demarcating old age clearly from social policy concepts such as retirement age, individual life transitions were suddenly subsumed into norms and expectations with 'old age' becoming an abstract concept to do with statistical likeliness. Hence, in the light of ever more diversified life courses, Baars and Grenier call for more attention to be paid to subjective interpretations, to the narrative that each individual formulates throughout their life course, and the resulting diverse experiences of later life and ageing.

\section{A move away from clearly defined stages of life}

Age demarcation lines vary, depending on whether studies look at old workers, the 'youngold' retirees and their activities, or the (often frail) 'oldest-old'. The term 'Fourth age' was introduced to refer to the latter. Laslett described the Fourth Age in reference to Shakespeare's already mentioned play as 'a condition of half-life, 'sans teeth, sans eyes, sans taste, sans everything' (Laslett, 1996: 20). Baltes and Smith offer a population-based definition of 'the 
transition between the Third and the Fourth Age [...] as being the chronological age at which 50 per cent of the birth cohort are no longer alive' in an attempt to increase 'the likelihood that people beyond that cut-off age are indeed subject to ageing processes' (Baltes and Smith, 2003: 125). They also point out that the individual transition between the phases can take place at very different ages, once more highlighting the conflict between the need to deal with large numbers of ageing people and their very individualized experience of ageing.

This logic of the stages of life assumes that the Third and Fourth Age are chronologically ordered. Gilleard and Higgs (2010), however, throw a different light on these categories by moving away from a fixed model of life stages to analysing the social imaginary surrounding old age. They argue that 'Third Age' is a synonym for everything that is positive in later life and consider Third Age studies to be 'distinguished by their focus on contingency, diversity, and difference'. The focus with Third Age is therefore the continued agency of a person, of their individualistic, consumption oriented lifestyles that in many respects equal that of younger adults, with the bonus of having more spare time. In contrast, the 'Fourth Age' marks a space 'where power, status, and citizenship can no longer be enacted' (ibid.). It is defined by the loss of agency, by the loss of choice and the loss of the ability to be active that so define the modern day individual and thus called 'the passing beyond the social world' or 'the new old age' (Gilleard and Higgs 2011: 125). In Modernity, however morbidity in younger years is significantly reduced and care for the ill, the frail (no matter if young or old) and the dying is often institutionalized and thus far removed from everyday life experience. Here frailty has gained a different weight and is loaded with the fear of the unknown and uncontrollable.

At first glance, these descriptions seem to suggest that Third and Fourth Age form opposing poles of later life. However, as Gilleard and Higgs (2010: 122) point out, not taking part in Third 
Age - people not defining themselves by how 'successfully' they (do not) age (in bodily appearance or physical and mental performance)-does not automatically locate people in the Fourth Age. Has research a blind spot in this regard? Does our binary thinking in categories of good and bad lead us to overlook a part of the older population?

\section{Methodology \& Data}

This paper addresses three aspects of dependency/contribution in old age in the domains health, finance, and unpaid care, following these research questions:

1. Does increasing life expectancy mean that people spend more years in poor health?

2. Are older adults dependent on other people's productivity?

3. Are older adults exhausting informal care resources?

These questions are tested with the help of publicly available aggregated census, registry and survey data from the UK, particularly from England. However, population ageing is a trend covering many countries and the UK here merely serves as a case study.

Seven data sources were used to answer the research questions. This was necessary due to the diverse nature of the aspects of old age covered in this paper that could not be addressed with a single data source. To answer research question 1, firstly data from the Human Mortality Database (www.mortality.org) was consulted to look at the development of life expectancy (LE) over the course of the $20^{\text {th }}$ century. Subsequently, data from Bebbington (1988) and the Office for National Statistics $(2004 ; 2012 ; 2017 a)$ were combined to look at the development of LE and disability-free life expectancy (DFLE) between 1977 and 2015. DFLE equals the number of years lived free from limiting long-standing illness. The cited authors calculated this following the Sullivan method by using ONS mid-year population estimates and period life tables, along 
with survey data from the General Household Survey (GHS) on the existence of any longstanding illness, disability or infirmity that limit individual activities in any way. To prevent bias from extreme values, three year moving averages were utilised. Results are shown for England.

The second research question, whether older adults are dependent on younger adults' productivity, was addressed with the help of three distinct pieces of analysis. First, economic activity was examined using data from the most recent Census conducted in England and Wales and results from the Labour Force Survey (LFS) conducted at the same point in time. The population was everyone who lived in England in March 2011. Age groups were determined by the census output. The 2011 UK census provided data on the economic activity rates of residents in England between the ages of 16-74, while the 2011 LFS provided data for people aged 75 and over. Both the LFS and the census automatically assumed economic inactivity for every person under the age of 16 . Secondly, poverty rates for three population groups, including pensioners, were discussed using data from the Institute for Fiscal Studies. These rates cover Great Britain from 1961 to 1993 and the UK from 1994 to 2016-17 and are based on the definition of relative poverty $(60 \%$ of net [after taxes and benefit transfers] median household equivalised income after housing costs). Lastly, contribution through volunteering is illustrated with data from the 2017-18 Community Life Survey with the help of a representative sample of people in England aged 16 and over. Formal voluntary work is defined here as 'unpaid help to any groups, clubs or organizations'. Informal volunteering encompasses a wide range of unpaid aids given to a nonrelative, such as baby-sitting, pet-sitting, household chores, writing letters or filling out forms (DCLG, 2010: 20).

The research question about whether older adults exhaust informal care resources is again responded to with the help of UK census data that contains information on who provides 
informal care (although not to whom). Thus, this paper captures how much informal care is provided by older adults, not how much is used. We were unable to find information on the latter question.

\section{Results}

Does increasing life expectancy (LE) mean that people spend more years in poor health?

Contrary to much popular thinking, the longer LE that today's older people are facing does not necessarily imply more years in bad health (Lutz and Scherbov, 2005). Recent studies also suggest either that limitations and disabilities are being postponed or morbidity is being compressed, despite an increase in chronic diseases and conditions (Crimmins, 2004; Martin et al., 2010; Parker and Thorslund, 2007).

While the latter point about compressed morbidity at first appears to be contradictory, it is at least partly explained by the spread of earlier diagnosis, improved treatment, and amelioration of prevalent diseases so that they are less disabling (Parker and Thorslund, 2007). Analysing data for the UK from the Human Mortality Database, we observe that while LE at age 65 has been increasing almost monotonically among men since the 1960 s and as early as the 1920 s in the case of women, this was not accompanied by similar increases in DFLE until around the mid1980s. However, during the next two decades, especially in the case of women, DFLE increased at a faster rate for the $65+$ population than LE, although the trend during the last decade appears to have been less favourable (Figure 1). The former result is consistent with findings from the Cognitive Function and Ageing Study (CFAS), which showed that the proportion of life expectancy without disability decreased between 1991 and 2011 (Jagger et al., 2016). However, the current trend is less well-defined (see the discussion). 
Figure 1: Life expectancy (LE) at age 65, Disability Free Life Expectancy (DFLE) at age 65 and DFLE as a proportion of LE at age 65 in England, 1977-2015 (3-year moving averages plotted on central year).

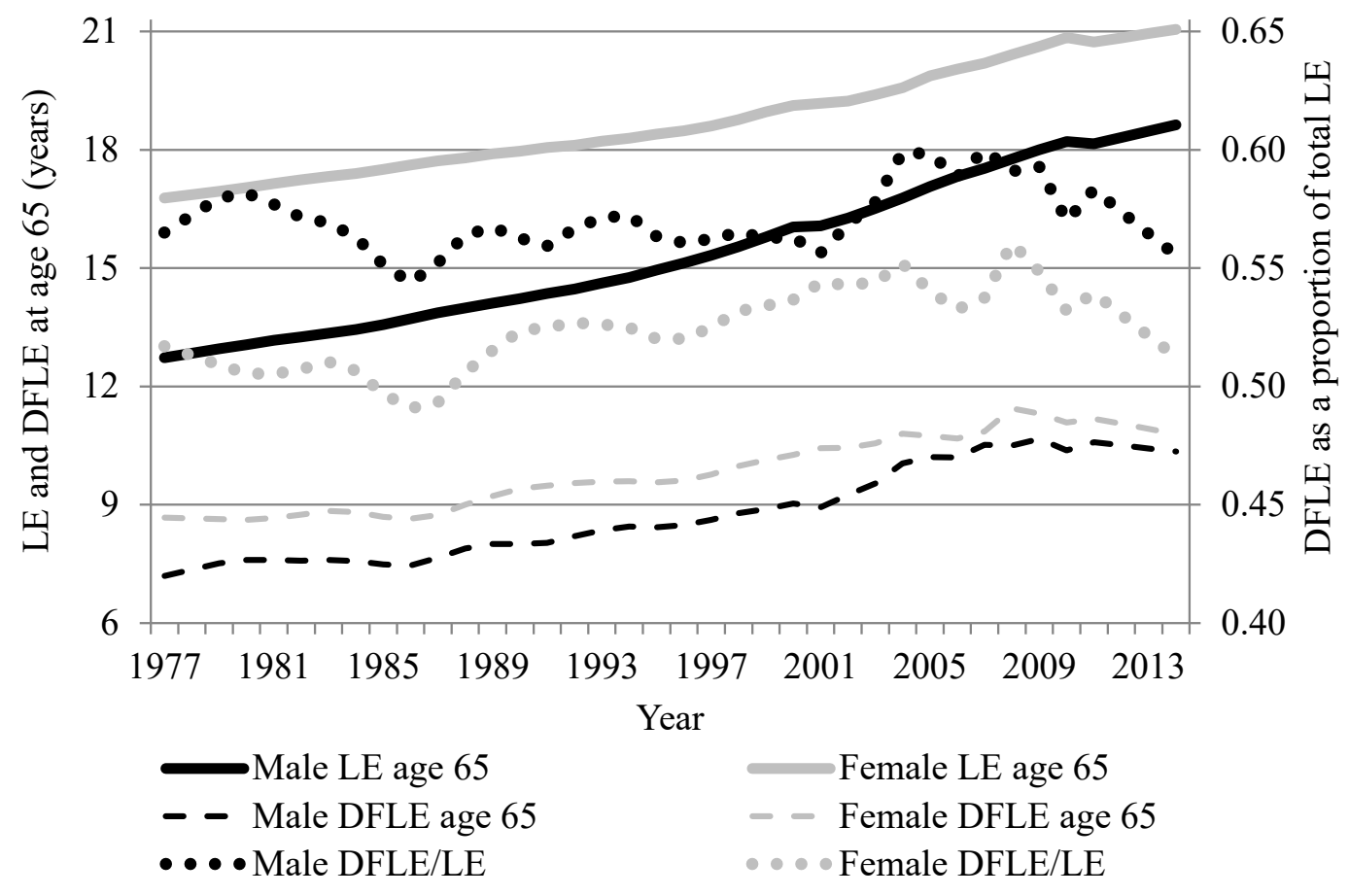

Source: Calculations based on figures published in Bebbington (1988) and ONS (2004; 2012; 2017a). DFLE is based on the General Household Survey (GHS) question "Do you have any long-standing illness, disability or imfirmity?". DFLE as a proportion of total LE was calculated by the authors of this article. The exact data points shown in this and the remaining figures can be obtained upon request from the authors.

Are older adults dependent on other people's productivity?

Economic dependency is an issue with, at best, a complex relationship to age. Not all old people are economically dependent, while many young adults are in this situation. 49.2 per cent of people aged 16-24, 19.6 per cent of people aged 25-49, and 60.2 per cent of people aged 50-75 
were considered economically inactive in England in 2011, while 2.9 per cent of the respondents aged 75 or over were still counted as economically active. Figure 2 compares economic inactivity rates by age groups. Included in this figure are fulltime students without employment (71.7 per cent of all fulltime students between the ages of 16-74), people who are seeking a job (these are labelled as economically active in the census, since they are theoretically available for the labour market, but are perhaps better described as involuntarily inactive), long-term sick or disabled, looking after home or family, retirees, and people who are economically inactive for other reasons.

This means that the English population under 16 has a share of 31.7 per cent of the economically inactive; the retirees make up 41.3 per cent, which still leaves 27.1 per cent to those people in working age (see Figure 3 for a breakdown by the form of economic inactivity). These figures do not take into account any benefits economically active people may claim. According to the 2011 census 1.3 million employees (5.3 per cent of the total) where receiving income support, including child, housing and tax benefits.

Figure 2: Comparison of rates of economically inactive people by age groups for England.

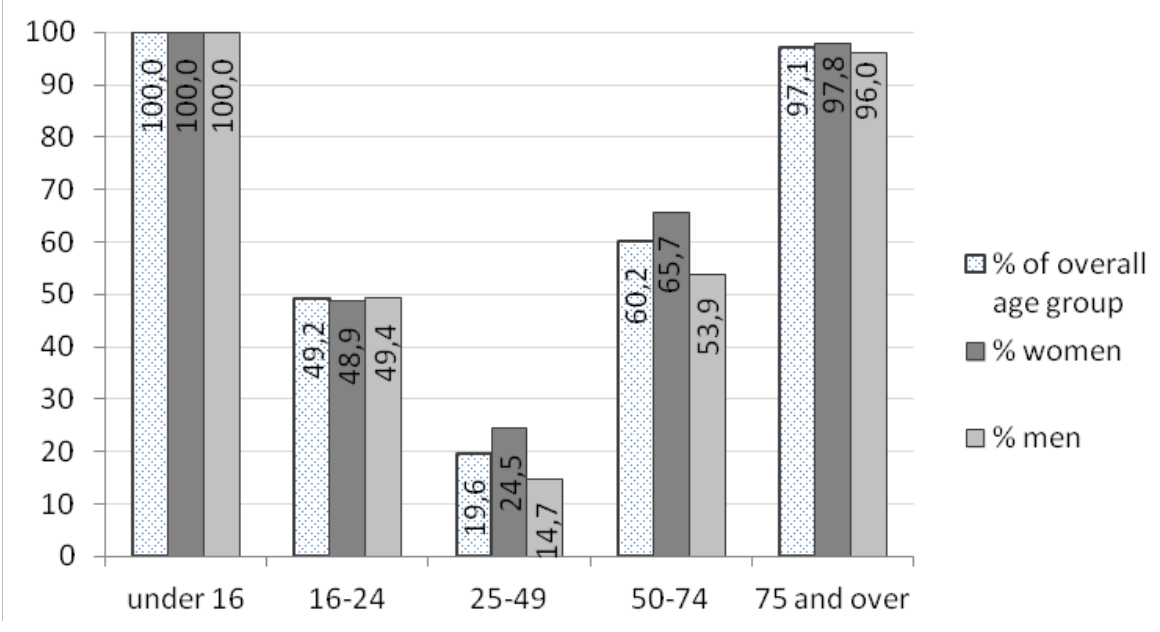


Source: Based on data from UK census of 2011 (ONS, 2013b) and LFS of 2011, $1^{\text {st }}$ quartile.

Figure 3: Comparison of different groups of economically inactive people for England.

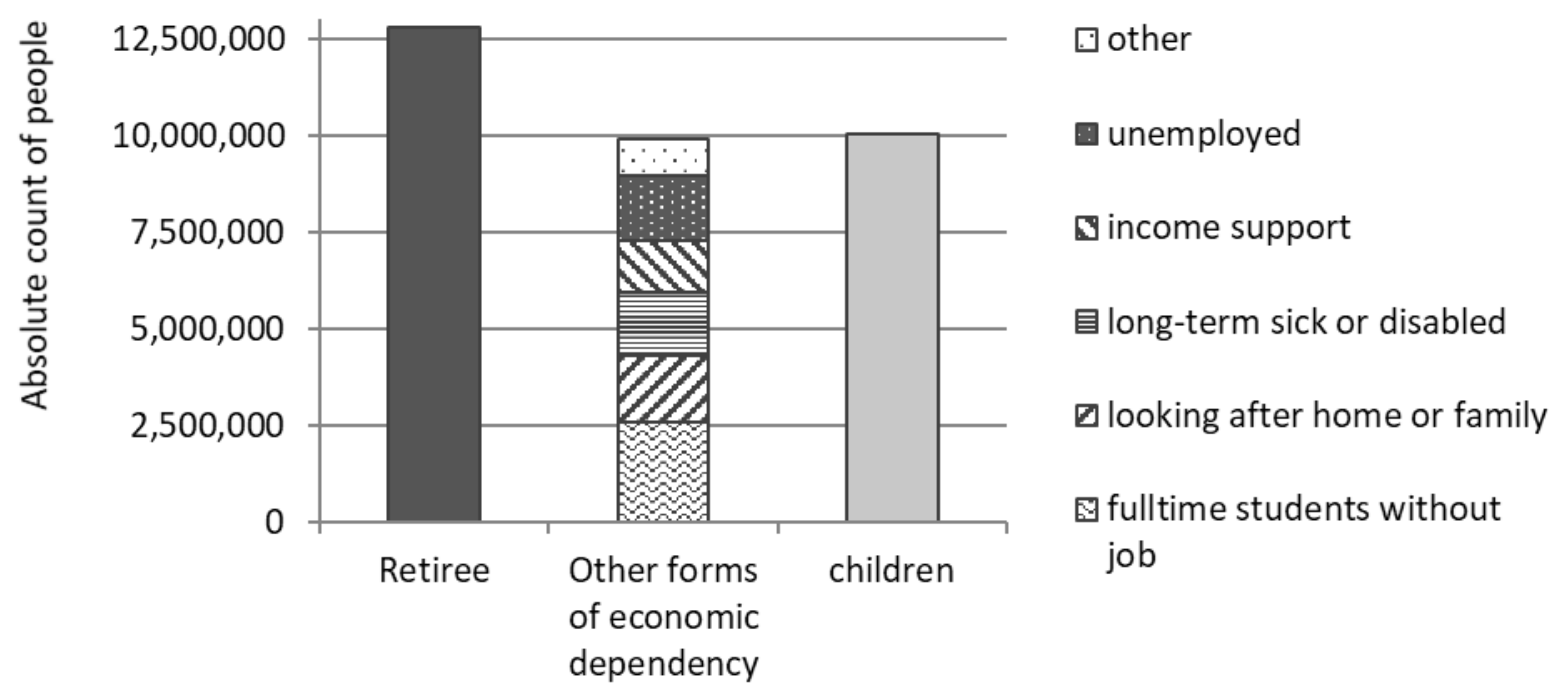

Source: Based on data from UK census of 2011 (ONS, 2013b) and LFS of 2011, $1^{\text {st }}$ quartile.

Another old myth is the conviction that old age means poverty. Between 1961 and 2016-17 absolute poverty fell as median equivalised household income after housing costs trebled and, as shown by Figure 4, this is particularly the case among pensioners. Half a century ago, two-fifths of pensioners were poor, compared to less than one in six today. Conversely, the rate of child poverty more than doubled in the 1980s and has not fallen substantially since then. This is reflected in a drop of the share of pensioners receiving benefits from 36 per cent in 1997/98 to $24 \%$ in 2017/18 (DWP 2019). 
Figure 4: Poverty rate for different groups within the population. 1961-2016-17. Great Britain/UK*

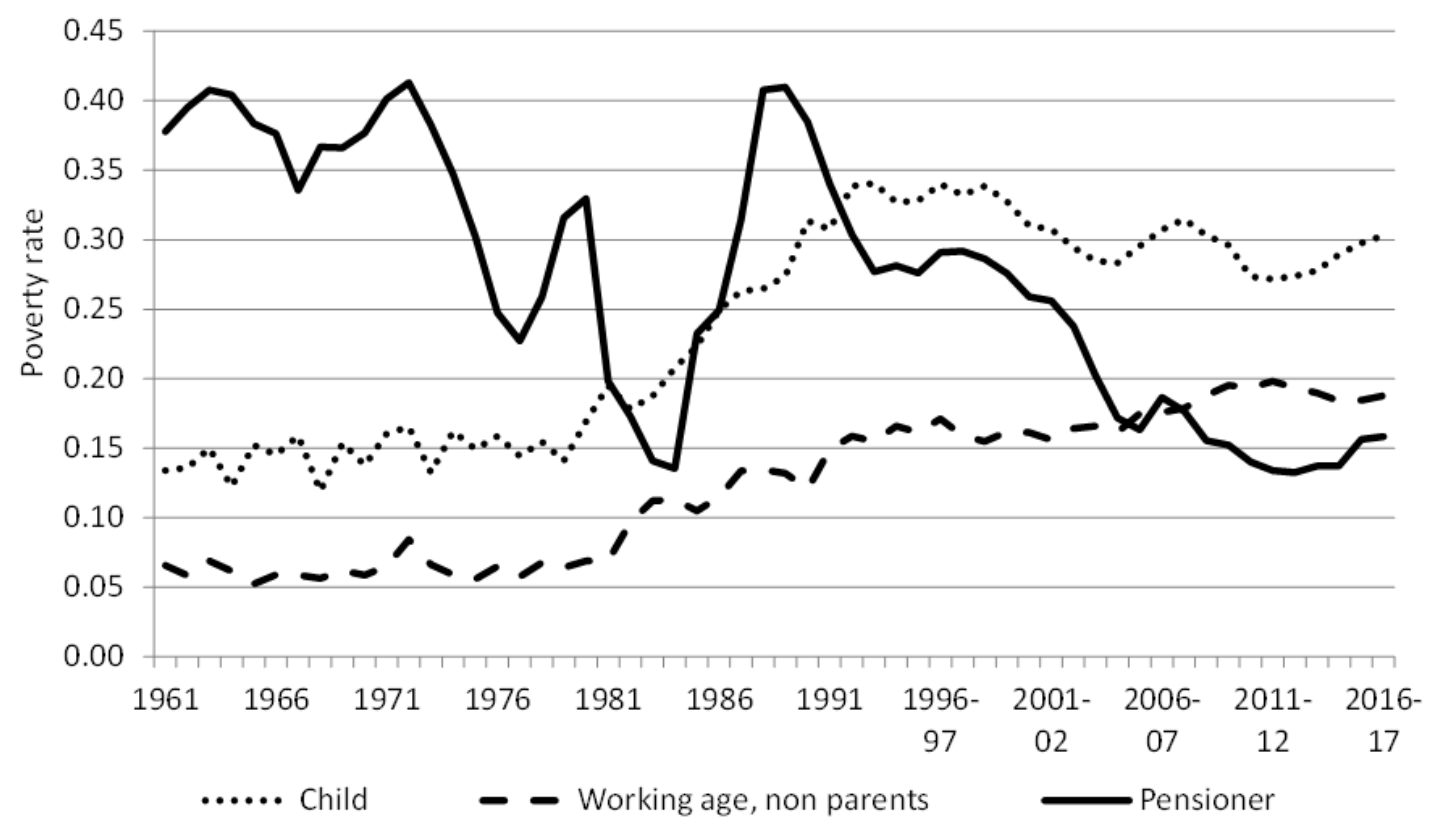

Source: Institute for Fiscal Studies (Cribb et al. 2018). Notes: Poverty defined as less than 60\% of net (after taxes and benefit transfers) median household equivalised income after housing costs. *Data for 1961-1993 is for GB in calendar years; from 1994 for tax years and UK.

The third piece of analysis on whether older adults are dependent on younger adults' productivity concerns volunteering. Volunteering has historically been one of the few formal roles available to older adults after exiting the workforce. Indeed, in England, older adults aged 65 and over are more likely to do formal voluntary work regularly than people of all younger age groups (table 1). Even of the oldest age group (75+) still one in four volunteered formally and about one in three volunteered informally at least once a month in 2017-18. 
Table 1. Participation in formal and informal volunteering at least once a month in England.

\begin{tabular}{|l|l|l|}
\hline \multirow{2}{*}{ Age group } & \multicolumn{2}{|c|}{ Volunteering } \\
\cline { 2 - 3 } & Formal (\%) & Informal (\%) \\
\hline $16-24$ & 24 & 28 \\
\hline $25-34$ & 15 & 24 \\
\hline $35-49$ & 21 & 22 \\
\hline $50-64$ & 24 & 25 \\
\hline $\mathbf{6 5 - 7 4}$ & $\mathbf{2 9}$ & $\mathbf{3 4}$ \\
\hline $\mathbf{7 5}$ and over & $\mathbf{2 5}$ & $\mathbf{3 4}$ \\
\hline
\end{tabular}

Source: 2017-18 Community Life Survey (DDCMS, 2018). In bold: population 65+.

Are older adults exhausting informal care resources?

Due to the constantly improving health of the retirees, retirement has long ceased to be the general withdrawal from society - if indeed, such a withdrawal indeed ever existed, as Cumming and Henry already asserted in 1961. Perhaps paradoxically, one area in which older adults play a vital role is that of care-giving. According to the 2011 census, there were nearly 1.2 million people aged 65 and over in England providing unpaid care, i.e. there were more care-givers amongst the older adults than there were people living in communal establishments within the whole population $(952,525)$. Figure 5 suggests at first glance that the peak of the share of caregivers is reached amongst the 55-59 year-olds and that care-giving swiftly declines afterwards. However, if we take into consideration the amount of time devoted to care by each person, we find that in younger years, 'part-time' care-giving was most frequent, whereas older adults spent much more time on their responsibilities, so that carers investing as much as 50 or more hours a week were in fact most frequently found amongst the 80-84 year-olds. Over 457,000 people aged 65 and over answered that they spend 50 or more hours per week on nursing someone; more than a third of them had already seen their 80th birthday. 
While people of the ages 65 or over made up only 16.3 per cent of the whole English population in the 2011 Census, they included 22 per cent of all carers. In this age group, 16.9 per cent spent up to 19 hours per week on care, 21 per cent invested 20-49 hours per week, and 36.5 per cent devoted over 50 hours per week with a tendency to rise further (Carers UK, 2012). Figure 5 shows that the share of people providing $50+$ hours of unpaid care and support was strongly associated with age, with older adults much more likely to provide this intense care.

Figure 5: Percentage of care-givers by age groups in England.

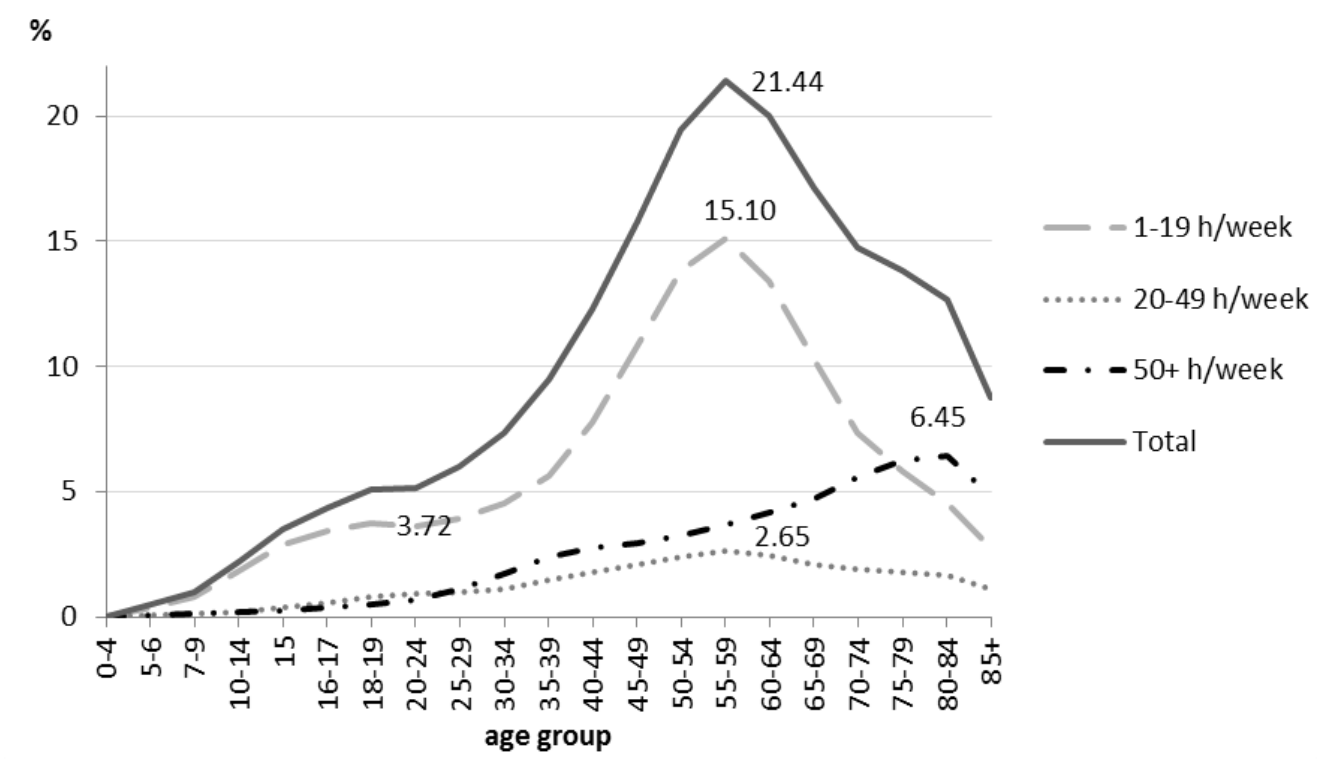

Source: Based on English data from the UK census of 2011 (ONS, 2013a).

Crosstabulation of providing unpaid care and general health (table 2) among the English population aged $65+$ shows that more people in fair health - as opposed to good or very good, health - provide unpaid care, with a small percentage point difference of 0.3. People in bad or very bad health are less likely to provide unpaid care (11.8\% compared to $14.6 \%$ among people in good and very good health). 
However, the majority of people in good and very good health who provided unpaid care did so for less than 20 hours per week (59.4\%), whereas 59.3\% of those carers in fair health and $70.9 \%$ of those carers in bad or very bad health provided $20+$ hours of unpaid care per week.

Table 2: People aged $65+$ providing unpaid care by general health status (self-assessed) in England.

\begin{tabular}{|l|r|r|r|}
\hline & $\begin{array}{r}\text { Very good or } \\
\text { good health }\end{array}$ & Fair health & $\begin{array}{r}\text { Bad or very } \\
\text { bad health }\end{array}$ \\
\hline All categories: Provision of unpaid care & $4,226,692$ & $2,907,419$ & $1,208,897$ \\
\hline Provides no unpaid care & $85.4 \%$ & $85.1 \%$ & $88.2 \%$ \\
\hline Provides unpaid care: Total & $14.6 \%$ & $14.9 \%$ & $11.8 \%$ \\
\hline Provides 1 to 19 hours unpaid care a week & $8.6 \%$ & $6.0 \%$ & $3.4 \%$ \\
\hline Provides 20 to 49 hours unpaid care a week & $1.6 \%$ & $2.1 \%$ & $1.8 \%$ \\
\hline Provides 50 or more hours unpaid care a week & $4.3 \%$ & $6.7 \%$ & $6.6 \%$ \\
\hline
\end{tabular}

Source: Based on data from UK census 2011 (table DC3301EW).

\section{Discussion}

While many will argue that the retirees are a proportionally larger 'burden', economic dependency remains an issue with, at best, a complex relationship to age. Not all older people are economically dependent, while many young people are in this situation. Moreover, pensioners have paid into the pension system throughout their working lives.

Perhaps equally important is the fact that while older adults made up 41 per cent of all economically inactive people in England in 2011 in terms of paid work, they, according to our results, at the same time contributed to their communities more than any other age group. This was done through volunteering and the provision of unpaid care and support to others. Moreover, people aged 65 and over were one of the most affluent age groups and thus an important consumer group for the economy. This consumption includes paid care services. The worry that 
growing LE will lead to long years of poor health may have been justified in the early stages of this development, but between the mid-1980s and late 2000s, DFLE has risen faster than overall LE in England.

This trend towards a longer disability free lifespan is important in light of work conducted by Lutz and Scherbov (2005) who showed that if such a trend were to occur, the increase in care need in European countries caused by population ageing would be low or non-existent. Unfortunately, the described trend towards higher DFLE in the UK has disappeared in the last decade, as has that towards higher healthy life expectancy (ONS, 2018a). This latter development could be ascribed as what Robine and Michel (2004) call "disability transition," in which morbidity expands again due to the emergence of very old and frail populations. The rise of overall life expectancy has likewise slowed or stalled altogether, not only in the UK but also in Iceland and the USA, although other countries, particularly Korea, Japan and countries of Eastern Europe have fared much better (Fenton et al, 2019).

In the context of population ageing and stalling increases in LE and DFLE in the UK, what does this imply in terms of the absolute number of older people with disability? Based on observed cardiovascular, dementia and other disease-related disability trends between 2002 and 2013, Guzman-Castillo et al. (2017) estimated that between 2015 and 2025 people in England and Wales aged 65 years LE would increase by 1.7 years, with about $40 \%$ of these extra years involving disability. Accordingly, during this decade the overall number of people experiencing disability is expected to grow by 560,000 cases to 2.8 million older people, although the authors state that is primarily as a consequence of population ageing rather than an increase in the prevalence of disability. 
Nevertheless, further analysis would be beneficial to determine the actual time spent in poor health or with limitations in activities of daily living and their trends over time. Just because a person experiences a phase of poor health, e.g. due to cancer, does not mean they do not recover to experience many more healthy years. This is not considered by the above-discussed measures. At this point, research question one, whether rising LE leads to more years in poor health, given the evidence of our and other studies, cannot be refuted, at least for the UK, although it must be acknowledged that rising LE also leads to additional health years.

Healthy LE is higher among affluent people. It thus stands to reason that its rise went along with a strong reduction of poverty among older adults. This stands in contrast to increased poverty rates in younger population groups. In 2011 the median income of pensioners after deducting housing costs exceeded that for non-pensioners for the first time (Cribb et al., 2018). Pensioners today are richer and healthier than they have ever been. In 2014-16 the median net wealth per person aged $65+$ in Britain was a little over $£ 400 \mathrm{k}$, substantially higher than for all other age groups, except those about to become pensioners (aged 55-64) (ONS, 2018b). With the rise in wealth and their swelling numbers, older adults have become an important consumer group (UNECE, 2009), and they provide essential financial support for the younger generations of their families (Brandt et al., 2009). Our analysis showed that with 41\%, they made up the biggest group of 'economically inactive' people in terms of waged work, yet it has to be pointed out that the income they do receive is a result of their past labour, so that whether they are financially dependent in the same way as people in unemployment, for example, is questionable.

Furthermore, people aged 65 and over are the most engaged population group in the provision of unpaid volunteer work in England, an area of productivity contributing more than $£ 22 \mathrm{bn}$ yearly to the UK economy (ONS, 2017b). While voluntary engagement rates dropped in the 
population after 2005, they did not do so among those aged 65 and over (DCLG, 2010; DDCMS, 2018). Pensioners are not equally as active in this sector in other countries, but volunteer rates among older adults have been rising (Morrow-Howell, 2010) - fuelled, perhaps, by the 'busy ethic' (Ekerdt, 1986) and by the positive effect this has on older adults' wellbeing (Jenkinson et al., 2013).

Research question two, whether older adults depend on other people's productivity, has to be answered with yes, but only because everyone depends on a networked society. Older adults also make substantive contributions.

Their contribution via unpaid work also reaches into the realm of personal care. Older adults invested more time when they were unpaid carers. This finding can be attributed to the large share of spousal care. An underappreciated aspect is the one that emerges when looking at general health status of carers aged 65 and over. While a slightly lower share of people in poor health provide care compared to those in fair and good health, people in fair and bad health were more likely to provide a high amount of care (50+ hours per week) compared to those in good and very good health. This may again be related to spousal care, where both partners have been living in the same conditions for a long time (such as diet, environmental factors, physical activity) and thus experience a parallel development in their health.

Research question three, whether older adults exhaust informal care resources, therefore has to be answered in the negative: older adults may need much informal care, but they are also a substantive source of it. To illustrate, the number of carers over the age of 65 is increasing more rapidly than the general carer population. A recent UK poll suggests that the number of unpaid carers aged 65 years or over there has grown from 1.4 million at the time of the 2011 census to over 2 million in 2019 (Carers Week, 2019a). This growth (+43\%) is faster than the growth of 
the $65+$ population as a whole during this period $(+18 \%)$. A point for further analysis here would be an estimation of the value of unpaid care rendered by older adults. Carers UK (2019b), estimate that each carer saves the economy an average of $£ 19,336$. With older carers on average investing more hours, their contribution will be even higher.

\section{Strengths \& Limitations}

Most of the empirical evidence used for this paper is based on population data from public sources, offering results that are not affected by sampling bias. The evidence provided critically highlights the complexity of population ageing - with positive and negative aspects - that is often overlooked in the public discourse. However, this complexity means that not all questions around population ageing could be addressed and not all addressed questions could be covered in full depth or for a more recent period. For example, we still had to resort to the 2011 census data to obtain the exact number of retirees and other economically inactive people, while the data does not provide an estimate of the financial impact of the different types of economic inactivity.

\section{Conclusions}

As Minois (1989) pointed out three decades ago, societies have long held mixed views about ageing, as if it was a universal dimension. Historically, older people were firmly ensconced as dependents as their numbers were relatively few, urbanization and changing family structures undermined long-standing sources of economic support, and their collective existence was highly marginalized (Hudson and Gonyea, 2012; Wilensky and Lebeaux, 1965). The political influence of older adults was limited due to their small numbers, and their marginal status placed their fate largely in the hands of others: family members within the informal world and public relief within 
the formal world. It was this predicament that made older people a target of reformers and advocates in the early 20th century (Hudson and Gonyea, 2012), although notable improvements in their economic and social well-being did not occur until after WWII when their rising numbers prompted more political leverage (Schneider and Ingram, 1993).

New political realities, however, appear to be threatening the advantaged status of older people in domestic social policy (Hudson and Gonyea, 2012). Particularly the growth in their numbers (and proportion) has led to concern from national governments, about how 'population ageing' will affect pension and healthcare systems (examples for the UK include Burnside, 2012; the House of Lords Select Committee on Public Service and Demographic Change, 2013). Hudson and Gonyea (2012) therefore argue that the "looming boomers" will need to contend for their political legitimacy: "In particular, the question becomes whether 'the aged' are viewed as less deserving of or entitled to benefits than was earlier the case" (p. 277).

In addition, public opinion on older people is also divided. There are those who strongly support older people and their needs, while others question the viability of social welfare programmes to which they are entitled (Hudson and Gonyea, 2012) and negatively stereotype older individuals, even excoriating them, especially through social media (Levy et al., 2014).

Amid these perceptions and concerns surrounding old age and population ageing, in this paper we analysed three areas that are often stereotypically used against older people: their supposed poor health, dependency on other people's productivity, and being mainly at the receiver's end of the care cycle. We have shown that old age has flipped from being a period of penury, ill-health and the prospect of death a century ago, to the stage in the life course where there is still a high chance of living most of the additional years in good health (Figure 1). Moreover, older people today are living these additional years by being more physically active than earlier cohorts 
(Duijvestijn et al., 2020; Stamatakis et al., 2007) and contributing to their communities more than any other age group through volunteering and the provision of unpaid care and support to others (Table 1).

Important to note also is that today's pensioners have a lower risk of poverty than other ages. At the same time, it is unfortunate that claims about the unsustainability of our current welfare system and healthcare arrangements are based on examining misleading indicators, such as the proportion of the population older than 64 or dependency ratios calculated using static population age structures. Such indicators overlook the dynamics of population ageing and the labour market (Spijker and MacInnes, 2013b), as well as the fact that people of working age depend on the unpaid domestic and caring work, often undertaken by pensioners and children (Bytheway, 2011). We should therefore not succumb to the kind of moral panic based on dependency ratios in which ageism flourishes and the lives and well-being of older people are put at risk (Thane, 2000). Instead, a carefully operationalised measure of dependency may fulfil the function of a binary parting of the population into contributors and receivers much better than age, but even then a person may well fall into both categories (as the number of unpaid carers in advanced age and in poor health suggests). Ultimately, the question needs to be raised whether such a distinction is indeed necessary and whether we should narrow our view of the members of our society to it. We therefore recommend more research into the heterogeneity of the older population focusing not on what sets the population apart, or discussing relations between the non-old and old in terms of 'us' and 'them' (Bytheway, 1995), but simply treating older adults as a part of the adult population.

\section{References}

Baars J (2012) Aging and the Art of Living. Baltimore: JHU Press. 
Baltes PB and Smith J (2003) New Frontiers in the Future of Aging: From Successful Aging of the Young Old to the Dilemmas of the Fourth Age. Gerontology 49: 123-135.

Bebbington AC (1988) The expectation of life without disability in England and Wales. Social Science \& Medicine 27(4): 321-326.

Brandt, M, Haberkern, K, and Szydlik, M (2009) Intergenerational help and care in Europe. European Sociological Review, 25(5), 585-601.

Burnside R (2012) Demographic Change (Financial Scrutiny Unit Briefing 12/57). Edinburgh: Scottish Parliament Information Centre (SPICe).

Bytheway B (1995) Ageism. Open University Press: Buckingham.

Bytheway B (2011) Unmasking age: The significance of age for social research. Bristol: Policy Press.

Carers UK (2012) Facts about carers 2012. Policy briefing. Available from: https://www.bl.uk/collection-items/facts-about-carers-2012

Carers UK (2019a) Research Summary Carers Week 2019. Available from: https://www.carersweek.org/images/CW19_Research_Report_web.pdf

Carers UK (2019b) Facts and Figures. Available from: https://www.carersuk.org/news-andcampaigns/press-releases/facts-and-figures

Cribb J, Norris Keiller A and Waters T (2018) Living standards, poverty and inequality in the UK: 2018. London: The Institute for Fiscal Studies. Available from https://www.ifs.org.uk/tools and resources/incomes in uk, including spreadsheet.

Crimmins EM (2004) Trends in the Health of the Elderly. Annual Review of Public Health 25(1): 79-98.

Cumming E and Henry WE (1961) Growing old, the process of disengagement. New York: Basic books

DCLG (Department for Communities and Local Government) (2010) 2008-09 Citizenship Survey-Volunteering and Charitable Giving Topic Report (Report No. 10CA06356).

DDCMS (Department for Digital Culture Media \& Sport) (2018) Community Life Survey 201718.

Duijvestijn M, van den Berg SW and Wendel-Vos G (2020) Adhering to the 2017 Dutch Physical Activity Guidelines: A Trend over Time 2001-2018. International Journal of Environmental Research and Public Health 17(3): 681. 
DWP (Department for Work and Pensions) (2019) Pensioners' Incomes Series: An analysis of trends in Pensioner Incomes: $1994 / 95$ to $2017 / 18$. Available from:

https://assets.publishing.service.gov.uk/government/uploads/system/uploads/attachment_data/ file/822623/pensioners-incomes-series-2017-18-report.pdf

Ekerdt DJ (1986) The busy ethic: Moral continuity between work and retirement. The Gerontologist 26: 239-244.

European Observatory on Health Systems and Policies (2006) The Health Care Workforce in Europe, Learning from experience. Available from: http://www.euro.who.int/ data/assets/pdf file/0008/91475/E89156.pdf?ua=1

Fenton L, Minton J, Ramsay J, Kaye-Bardgett M, Fischbacher C, Wyper GM, McCartney G (2019) Recent adverse mortality trends in Scotland: comparison with other high-income countries. BMJ Open:e029936 doi:10.1101/542449.

Gilleard C and Higgs P (2010) Aging without agency: Theorizing the fourth age. Aging \& Mental Health 14(2): 121-128.

Gilleard C and Higgs P (2011) Frailty, disability and old age: A re-appraisal. Health 15(5): $475-$ 490.

Grenier A (2012) Transitions and the Lifecourse: Challenging the Constructions of'growing Old. Bristol: Policy Press.

Guzman-Castillo M, Ahmadi-Abhari S, Bandosz P, et al. (2017) Forecasted trends in disability and life expectancy in England and Wales up to 2025: a modelling study. The Lancet Public Health 2: e307-e313.

Health Foundation (2019) Executive summary: Trends in the NHS workforce. Available from: http://reader.health.org.uk/a-critical-moment/executive-summary-trends-in-the-nhs-workforce Holmes ER, Holmes LD (1995) Other cultures, elder years (2nd edition). Sage, London. Howdon D and Rice N (2018) Health care expenditures, age, proximity to death and morbidity: Implications for an ageing population. Journal of health economics 57: 60-74.

Hudson RB and Gonyea JG (2012) Baby Boomers and the Shifting Political Construction of Old Age. The Gerontologist 52(2): 272-282.

Jagger C, Matthews FE, Wohland P, et al. (2016) A comparison of health expectancies over two decades in England: results of the Cognitive Function and Ageing Study I and II. The Lancet 387: 779-786. 
Jenkinson CE, Dickens AP, Jones K, Thompson-Coon J, Taylor RS, Rogers M, et al. (2013) Is volunteering a public health intervention? A systematic review and meta-analysis of the health and survival of volunteers. BMC Public Health 13(1):1-10.

Laslett P (1996) A fresh map of life: the emergence of the Third Age. Cambridge, MA: Harvard University Press.

Levy BR, Chung PH, Bedford T, et al. (2014) Facebook as a Site for Negative Age Stereotypes. The Gerontologist 54(2): 172-176.

Lutz W and Scherbov S (2005) Will Population Ageing Necessarily Lead to an Increase in the Number of Persons with Disabilities? Vienna Yearbook of Population Research 2005: 219234.

Martin LG, Schoeni RF and Andreski PM (2010) Trends in health of older adults in the United States: Past, present, future. Demography 47(1): S17-S40.

Minois G (1989) History of Old Age: From antiquity to the renaissance. Cambridge: Polity Press.

Morrow-Howell N (2010) Volunteering in later life: Research frontiers. The Journals of Gerontology: Series B 65(4): 461-469.

Münch P (1998) Lebensformen in der frühen Neuzeit: 1500 bis 1800. Ullstein.

Neugarten BL (1974) Age Groups in American Society and the Rise of the Young-Old. The Annals of the American Academy of Political and Social Science 415(1): 187-198.

Ogg J. \& Rašticová M. (2020). Introduction: Key Issues and Policies for Extending Working Life. In: Ní Léime Á, Ogg J, Rašticová M, Street D, Krekula C, Bédiová M, Madero-Cabib I (eds) Extended Working Life Policies: International Gender and Health Perspectives. Cham: Springer International Publishing. pp 3-27. doi:10.1007/978-3-030-40985-2_1.

ONS (Office for National Statistics) (2004) Healthy Life Expectancy for Great Britain and England: Annual Estimates for 1981 to 2001: National Statistics Website Release, 22 July. Available from: http://www.ons.gov.uk/ons/rel/disability-and-health-measurement/healthexpectancies-at-birth-and-age-65-in-the-united-kingdom/1981-2001/index.html

ONS (Office for National Statistics) (2012) Reference table: Health Expectancies in the United Kingdom, 2000-2002 to 2008-2010. Available from:

https://www.ons.gov.uk/ons/rel/disability-and-health-measurement/health-expectancies-atbirth-and-age-65-in-the-united-kingdom/2008-10/rft-hle-ref-tables-2000-02-to-2008-10.xls 
ONS (Office for National Statistics) (2013a) UK Census 2011, table dc3301ew - Provision of unpaid care by general health by sex by age. Available from: https://www.nomisweb.co.uk/census/2011/dc3301ew

ONS (Office for National Statistics) (2013b) UK Census 2011, table dc6205ew - Economic activity by religion by sex by age. Available from: https://www.nomisweb.co.uk/census/2011/dc6205ew

ONS (Office for National Statistics) (2017a) Health state life expectancy by single year of age, England and Wales, England and United Kingdom, 2009 to 2011 and 2013 to 2015. Available from:

https://www.ons.gov.uk/file?uri=/peoplepopulationandcommunity/healthandsocialcare/health andlifeexpectancies/adhocs/008007healthstatelifeexpectancybysingleyearofageenglandandwal esenglandanduk2009to2011and2013to2015/hslesyoav3.xls

ONS (Office for National Statistics) (2017b) Changes in the value and division of unpaid care work in the UK: 2000 - 2015. Available from: https://www.ons.gov.uk/economy/nationalaccounts/satelliteaccounts/articles/changesinthevalu eanddivisionofunpaidcareworkintheuk/2000to2015

ONS (Office for National Statistics) (2018a) Changing trends in mortality in England and Wales: 1990 to 2017 (Experimental Statistics). Available from:

https://www.ons.gov.uk/peoplepopulationandcommunity/birthsdeathsandmarriages/deaths/arti cles/changingtrendsinmortalityinenglandandwales 1990to2017/experimentalstatistics

ONS (Office for National Statistics) (2018b) Net total wealth by age band of household reference person and region, Great Britain, July 2014 to June 2016.

Parker MG and Thorslund M (2007) Health Trends in the Elderly Population: Getting Better and Getting Worse. The Gerontologist 47(2): 150-158.

Parkin TG (2003) Old age in the Roman world: a cultural and social history. JHU Press.

Robine J-M and Michel J-P (2004) Looking forward to a general theory on population aging. The Journals of Gerontology Series A: Biological Sciences and Medical Sciences 59(6): M590M597.

Roebuck J (1979) When does" old age begin?: The evolution of the English definition. Journal of Social History 12(3): 416-428. 
Schulze G (2005) Die Erlebnisgesellschaft: Kultursoziologie der Gegenwart. Frankfurt am Main: Campus Verlag.

Schneider A and Ingram H (1993) Social construction of target populations: Implications for politics and policy. American Political Science Review 87(2): 334-347.

Select Committee on Public Service and Demographic Change (2013) Report of Session 201213: Ready for Ageing? HL Paper 140. London: The Stationery Office Limited.

Stamatakis E, Ekelund U and Wareham NJ (2007) Temporal trends in physical activity in England: the Health Survey for England 1991 to 2004. Preventive Medicine 45(11): 416-423. Spijker J and MacInnes, J (2013a). Population ageing in Scotland: Time for a re-think? Scottish Affairs, 85(1), 53-74

Spijker J and MacInnes J (2013b) Population ageing: the timebomb that isn't? British Medical Journal, 347, f6598.

Thane P (2000) Old age in English history: past experiences, present issues. Oxford: Oxford University Press.

Tölle D (1996) Altern in Deutschland: 1815-1933; eine Kulturgeschichte. Vektor-Verlag.

UNECE (United Nations Economic Commission for Europe) (2009) Older persons as consumers - A policy brief. Available from:

https://www.unece.org/fileadmin/DAM/pau/_docs/age/2009/Policy_briefs/Policy-briefOld_persons.pdf

Wilensky HL and Lebeaux CN (1965) Industrial society and social welfare. New York: Free Press. 